\title{
Experimental and finite element analysis of fracture criterion in general yielding fracture mechanics
}

\author{
D M KULKARNI ${ }^{1}$, RAVI PRAKASH ${ }^{2}$ and A N KUMAR ${ }^{3}$ \\ ${ }^{1}$ Mechanical Engineering Group, Educational Hardware Division, \\ Birla Institute of Technology and Science, Pilani 333 031, India \\ ${ }^{2}$ Research and Consultancy Division, Birla Institute of Technology and Science, \\ Pilani 333 031, India \\ ${ }^{3}$ Applied Mechanics, Indian Institute of Technology, New Delhi 110 016, India \\ e-mail: dmk@bits-pilani.ac.in
}

MS received 16 May 2002; revised 20 September 2002

\begin{abstract}
Efforts made over the last three decades to understand the fracture behaviour of structural materials in elastic and elasto-plastic fracture mechanics are numerous, whereas investigations related to fracture behaviour of materials in thin sheets or general yielding fracture regimes are limited in number. Engineering simulative tests are being used to characterize formability and drawability of sheet metals. However, these tests do not assure consistency in quality of sheet metal products. The prevention of failure in stressed structural components currently requires fracture mechanics based design parameters like critical load, critical crack-tip opening displacement or fracture toughness. The present attempt would aim to fulfill this gap and generate more information thereby increased understanding on fracture behaviour of sheet metals. In the present investigation, using a recently developed technique for determining fracture criteria in sheet metals, results are generated on critical CTOD and fracture toughness. Finite element analysis was performed to support the results on various fracture parameters. The differences are within 1 to $4 \%$. At the end it is concluded that magnitude of critical CTOD and/or critical load can be used as a fracture criterion for thin sheets.
\end{abstract}

Keywords. Extra deep-drawn steel sheets; fracture criterion; general yielding fracture mechanics; crack-tip opening displacement.

\section{Introduction}

In recent years, there have been considerable emphasis in the production of deep-drawn and extra deep-drawn (EDD) steel sheets in industries. The wide applications of EDD steel sheets are not only well-known for domestic appliances like storage containers, and household

A list of symbols is given at the end of the paper 
utensils but also in the automobile industry for manufacturing car bodies. With increasing global competition for quality materials, there is a need to understand the fundamentals of crack initiation in these bulk products.

The failure of thin sheets during forming occurs first by localized necking, which is then followed by fracture inside the neck. The characterization of thin sheets is presently being done with the help of empirical methods and engineering simulative tests like Erichsen cup test, Olsen cup test and hole expansion test. However, these tests described in Rao \& Emani (2000) are influenced by different material variables (like yield strength, modulus of elasticity, strain hardening coefficient, plastic anisotropy factor and strain rate sensitivity index) and the process variables (like punch and die geometry configurations, clearances etc.). Measure of cup depth and hole expansion in simulative tests is an empirical basis because cup depth or hole expansion brings out a relative engineering index for formability. However, these tests lack any fundamental scientific basis in such quantitative measurement. In intrinsic tests, formability limit diagram (FLD) or formability limit curve (FLC) give the combination of major and minor principal strains at which necking occurs. However, according to Wu et al (2000) the construction becomes tedious and consequently is limited in engineering applications. In the above-mentioned tests, in general, attempt is made to search for an engineering parameter, which indicates the mechanical environment for crack initiation and/or propagation under the corresponding experimental conditions for each of these tests. The event of crack initiation and propagation is commonly dealt with using fracture mechanics principles; but so far, little attention has been paid in this direction.

\section{Background}

The basic principle for obtaining fracture criteria of thin and tough sheets/plates according to Liu and his co-workers (Liu \& Ke 1976; Liu \& Kuo 1978; Liu 1981) is related to examinations of a strip-necking zone, which remains embedded inside the plastic zone ahead of a crack tip in a deformed specimen. The investigators have contended that such strip-necking phenomenon is governed by the ratio of the plastic zone size and the plate thickness $(B)$, and thus a physical parameter $\left(K / S_{Y}\right)^{2} / B$ controls the occurrence of crack tip necking. The parameter henceforth will be referred to as the strip necking parameter. In addition, Liu (1981), and Liu \& Kuo (1978) have observed that the crack tip opening displacement in the strip necking zone is equal to the thickness contraction at the crack tip,

$$
C T O D=\triangle B=\varepsilon_{z} \cdot B .
$$

This in turn is related to the stress intensity factor. The estimation of the stress intensity factor for tough and thin plates by Liu (1981) has been carried out following the Dugdale model (1960), using the relationship,

$$
J=K^{2} / E=S_{y} \cdot C T O D=S_{y} \cdot \Delta B .
$$

The salient conclusions of Liu's reports (1981) indicate that the near tip strain or crack tip contraction can be used as a fracture criterion. The replica technique was used for the detection of crack tip necking and the Moire fringe technique was used for the detection of crack tip opening displacement. However, these techniques could not become popular, as they are too elaborate for employment in the quality control of sheet metals in terms of fracture mechanicsbased criteria. In addition, these investigations have not indicated any rationale for detecting the crack initiation event. 


\section{Objectives}

The insufficient attention on studies related to fracture behaviour of sheet metals originates from the fact that engineering materials with thinner sections are not considered as load bearing structural parts. Only Liu and his co-workers (Liu \& Ke 1976; Liu \& Kuo 1978; Liu 1981) have suggested some guidelines to assess fracture criteria for thin and tough plates of structural materials. The objectives of this study are: (i) to present a simple experimental technique for obtaining fracture criteria of EDD steel sheets in line with the studies of Liu and others (Liu \& Ke 1976; Liu \& Kuo 1978; Liu 1981) and produce results on different fracture parameters, (ii) to examine the effect of the variation of thickness of such steel sheets on their fracture criteria and (iii) verification of these results by the finite element method.

\section{Methodology}

The determination of fracture criterion for thin sheets in the present study was made using compact tension type specimens as per ASTM (1991) and with the help of a fabricated grip. Various tests were conducted to conclude the results.

\subsection{Specimen preparation}

Specimens were fabricated according to ASTM (1991) by wire electric discharge machining to maintain the exact relationship between all the dimensions. The configuration of the test specimen is shown in figure 1 . The specimens were ground with emery papers following $1 / 0$ (coarse), 2/0, 3/0, 4/0 (fine). These were then polished first using alundum and finally using $0.25 \mathrm{~mm}$ diamond paste. The mechanical grip was fabricated suitable to the universal testing machine.

\subsection{Metallographic and mechanical tests}

The composition of the investigated steel was given $(\mathrm{C}-0.06, \mathrm{Mn}-0.38, \mathrm{~S}-0.03, \mathrm{P}-0.017$, $\mathrm{Si}-0.05, \mathrm{Fe}-\mathrm{The}$ balance, all in weight percent) from Scientific Services Division, Tata Iron Steel Co. Ltd. The microstructure of the material revealed ferrite plus pearlite $(\sim 5 \%)$, and the average ferrite grain size was found to be $7.2 \mu \mathrm{m}$. The average tensile properties of the material were as follows: yield strength $\left(S_{Y}\right)=335 \mathrm{MPa}$, ultimate tensile strength $=387 \mathrm{MPa}$ and modulus of elasticity $(E)=210 \mathrm{GPa}$. The average hardness of the steel in the Rockwell-B scale was obtained as 72 .
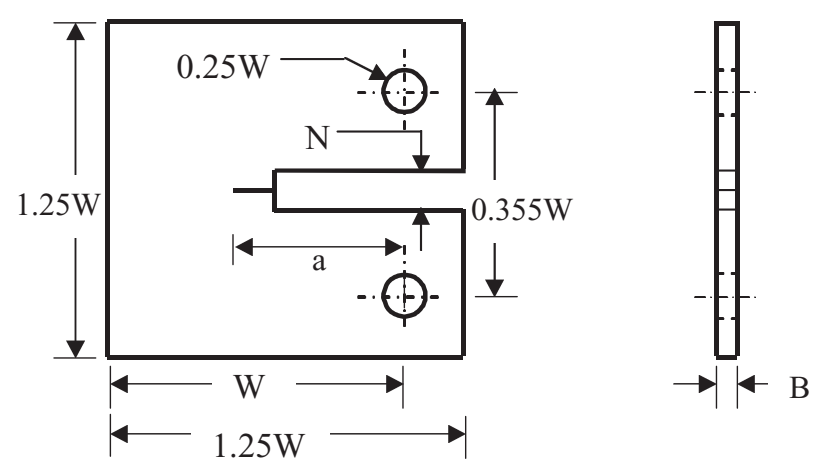

Figure 1. Geometry of the test specimens used for determining fracture criteria of thin sheets. $(W=24 \mathrm{~mm}$, $B=$ thickness, $N 1=0.8 \mathrm{~mm}$, and $a=$ initial crack length.) 


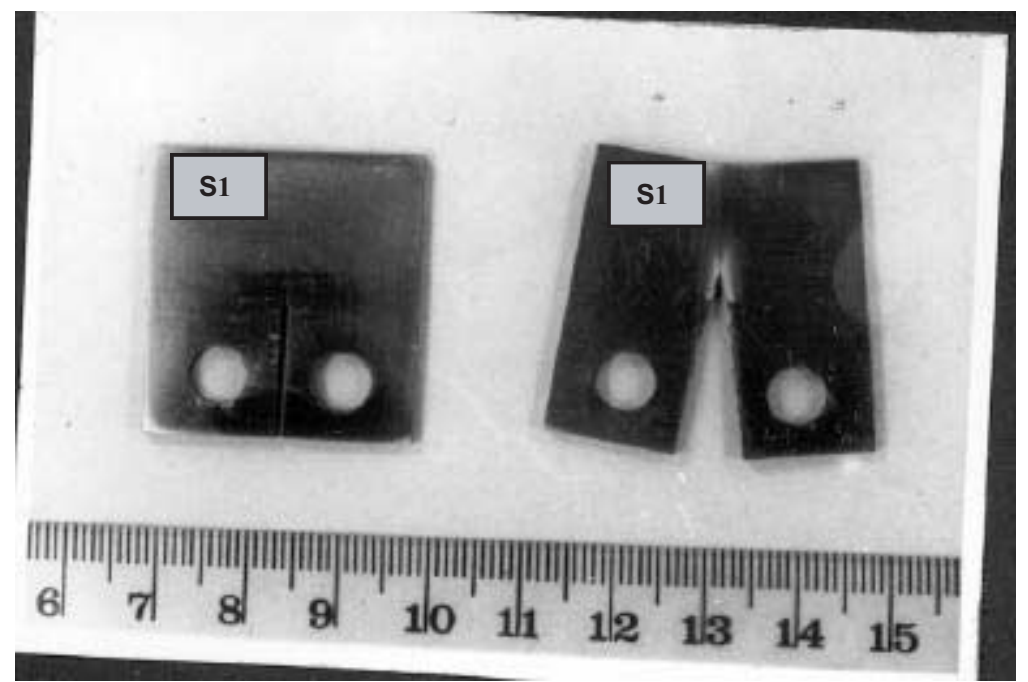

Figure 2. A photograph of a deformed specimen (right) together with an undeformed one (left).

\subsection{Fracture test and fracture criteria}

The fracture tests were carried out using an Instron (Model 4204) universal testing machine with a loading rate corresponding to the constant crack head displacement of $0.2 \mathrm{~mm} / \mathrm{min}$ at the room temperature of $300 \mathrm{~K}$. Lubricated shims were used on both sides of the specimen to ensure in-plane loading. During such tests, the magnitude of load $(P)$ and load line displacement $\left(V_{l l}\right)$ were recorded together with time. It was observed that load dropped at a particular instant when surface cracks (figure 2) initiated.

At that instance of time, the loading of a specimen was discontinued and the specimen was taken out for subsequent measurement of CTOD and analysis of alternate fracture criteria. A typical load-load line displacement plot is shown in figure 3. It is observed from figure 3 that the load continuously increases till a $P_{c}$ value, however, the rate of increment of load just before the critical load is very low as compared with the earlier portion of the plot. The rate of increment of load continues to decrease and as soon as surface crack initiates, the load drops.

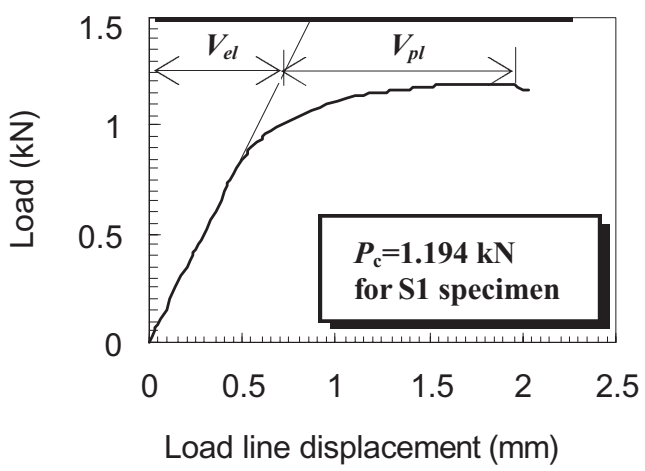

Figure 3. Load-load line displacement plot. 
Table 1. Dimensions of the tested specimens and the critical load $\left(P_{c}\right)$ attained during fracture tests.

\begin{tabular}{cccc}
\hline $\begin{array}{c}\text { Specimen } \\
\text { code }\end{array}$ & $\begin{array}{c}\text { Thickness } \\
B(\mathrm{~mm})\end{array}$ & $\begin{array}{c}\text { Crack length } \\
a(\mathrm{~mm})\end{array}$ & $\begin{array}{c}\text { Critical load } \\
P_{c}(\mathrm{kN})\end{array}$ \\
\hline S1 & 1.18 & 10.16 & 1.194 \\
S2 & 1.38 & 10.15 & 1.431 \\
S3 & 1.64 & 10.22 & 1.773 \\
S4 & 1.69 & 10.16 & 1.855 \\
\hline
\end{tabular}

Four specimens with thickness 1.18, 1.38, 1.64 and $1.69 \mathrm{~mm}$ were tested. The detailed dimensions of the specimens together with the critical loads obtained $\left(P_{c}\right)$ during their fracture tests are given in table 1.

\section{Results}

\subsection{Estimation of critical ctod and fracture toughness}

Following ASTM (1989) and Panontin et al (2000), the critical crack-tip opening displacement during the loading consists of elastic and plastic part,

$$
\begin{aligned}
\text { Critical CTOD } & =\text { Elastic CTOD + Plastic CTOD } \\
\delta_{c} & =\delta_{e l}+\delta_{p l} .
\end{aligned}
$$

In EDD steel sheet as the plasticity is more with low strain hardening the CTOD is measured at the tip of the crack.

5.1a Calculation for the elastic part $\left(\delta_{e l}\right)$ : The elastic part is calculated by a standard method,

$$
\delta_{e l}=K^{2}\left(1-v^{2}\right) / 2 E S y
$$

where elastic modulus $(E)$, Poisson's ratio $(v)$ and yield strength $\left(S_{y}\right)$ are the mechanical properties. The linear stress intensity factor $K$ for the CT specimens can be derived from Srawley's (1976) equation, as

$$
K=\left[P / B W^{1 / 2}\right] f(\alpha),
$$

where, $P=\left(P_{c}\right)$ load at crack initiation, $B$ is the thickness of specimen, $W$ is width of specimen and

$$
f(\alpha)=(2+\alpha)\left(0.886+4.64 \alpha-13.32 \alpha^{2}+24.72 \alpha^{3}-5.6 \alpha^{4} /(1-\alpha)^{3 / 2},\right.
$$

where, $\alpha=a / W$.

5.1b Calculation for the plastic part $\left(\delta_{p l}\right)$ : The plastic portion of $\operatorname{CTOD}_{c}\left(\delta_{p l}\right)$ is determined (Kumar 1991, 1995) by assuming that the uncracked ligament works like a plastic hinge with its centre at a distance $r_{p l} b$ from the crack tip as shown in figure $4 \mathrm{a}$. Referring to figures 4 


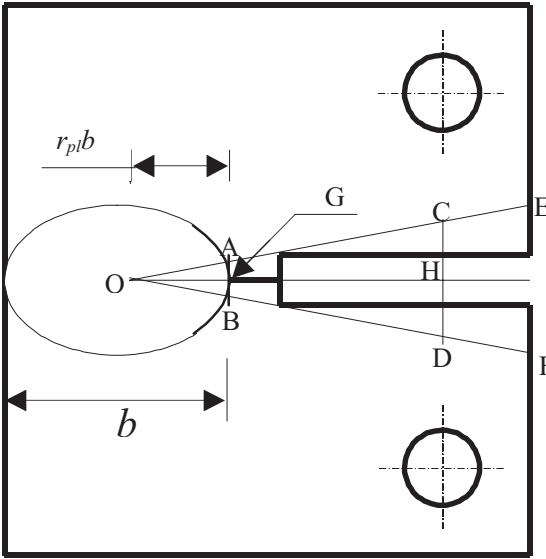

(a)

(b)

Figure 4. Calculation for the plastic part. (a) Plastic hinge model, and (b) crack-tip and load-line displacement geometry at crack initiation.

(a) and (b): $\mathrm{O}$ is the apparent axis of rotation, $\mathrm{G}$ is crack tip, $\mathrm{AB}$ is plastic part of the CTOD $\left(\delta_{p l}\right), \mathrm{CD}$ is plastic load line displacement $\left(=V_{p l}\right)$, and $\mathrm{GH}(=a)$ is initial crack length. The OG is taken equal to $r_{p l} b$, where $r_{p l}$ is a plastic rotational factor and $b$ is the ligament length. From properties of the similarity of triangles (figure $4 b$ ),

$$
\begin{aligned}
A B / C D & =O G /(O G+G H) \text { or } \delta_{p l} / V_{p l}=r_{p l} b /\left(r_{p l} b+a\right) \\
\delta_{p l} & =r_{p l} b /\left(r_{p l} b+a\right) V_{p l} .
\end{aligned}
$$

Equation (5) is based on the 'Plastic Hinge Model' (PHM), where the two halves of the specimen rotate about an apparent axis of rotation passing through point $\mathrm{O}$ and perpendicular to the plane of the specimen. According to Merkle \& Corten (1974) the value of plastic rotational factor $\left(r_{p l}\right)$ is based on fully plastic limit solution and is found to be $(1+\alpha) / 2$, where

$$
\alpha=\left[(2 a / b)^{2}+(4 a / b)+2\right]^{1 / 2}-[(2 a / b)+1] .
$$

The value for $V_{p l}$ is taken from figure 3. With the help of (3), (4) and (5), the value of critical CTOD $\left(\delta_{c}\right)$ is calculated for different thickness.

The value of the critical stress intensity factor is designated here as an equivalent fracture toughness value $K_{Q}$ instead of $K_{c}$, unlike Liu et al $(1976,1978)$ and (Liu 1981), because the stress singularity in general yielding fracture mechanics (GYFM) is an invalid concept. Equation (2) is used to find equivalent fracture toughness as Equation (6):

$$
K_{Q}=\left(\delta_{c} E S_{y}\right)^{1 / 2} .
$$

In another method, the plastic CTOD was estimated with the help of an Optical Microscope $(\mathrm{OM})$. The calculated values of $\delta_{e l}, \delta_{p l}(\mathrm{PHM}), \delta_{p l}(\mathrm{OM}), \delta_{c}(\mathrm{PHM}), \delta_{c}(\mathrm{OM}), K_{Q}(\mathrm{PHM})$ and $K_{Q}(\mathrm{OM})$ are listed in table 2 . 
Table 2. Experimental results on different fracture parameters.

\begin{tabular}{|c|c|c|c|c|c|c|c|c|}
\hline \multirow{2}{*}{$\begin{array}{l}\text { Spec. } \\
\text { code }\end{array}$} & \multirow{2}{*}{$\begin{array}{l}\text { Thickness } \\
B(\mathrm{~mm})\end{array}$} & \multicolumn{5}{|c|}{ Experimental CTOD results (mm) } & \multicolumn{2}{|c|}{$\begin{array}{c}\text { Equivalent fracture } \\
\text { toughness }\left(\mathrm{Mpa} \mathrm{m}^{1 / 2}\right)\end{array}$} \\
\hline & & $\delta_{e l}$ & $\delta_{p l}(\mathrm{OM})$ & $\delta_{p l}(\mathrm{PHM})$ & $\delta_{c}(\mathrm{OM})$ & $\delta_{c}(\mathrm{PHM})$ & $K_{Q}(\mathrm{OM})$ & $K_{Q}(\mathrm{PHM})$ \\
\hline S1 & 1.18 & 0.0373 & 0.516 & 0.556 & 0.553 & 0.593 & 197.23 & 204.24 \\
\hline S2 & 1.38 & 0.0391 & 0.557 & 0.600 & 0.596 & 0.639 & 204.77 & 212.04 \\
\hline S3 & 1.64 & 0.0425 & 0.636 & 0.674 & 0.679 & 0.716 & 218.55 & 224.43 \\
\hline S4 & 1.69 & 0.0438 & 0.773 & 0.801 & 0.817 & 0.844 & 239.74 & 243.67 \\
\hline
\end{tabular}

\section{Finite element formulation}

\subsection{Solid modeling and mesh generation}

The 3-dimensional geometry of a CT specimen was modelled as per ASTM standard (shown in figure 1). However, for mode I type modelling, by exploiting the geometry, loading, material and support symmetry conditions, only half of the geometry was modelled.

The element was defined by using 20 nodes having 3 degrees of freedom per node and translations in $x, y$ and $z$ directions as shown in figure 5a. Meshing was graded from fine at the crack tip to coarse at the solid boundary. The most important region in a fracture model is the region around the edge of the crack. Element size that ranges from $0.035 \%$ to $0.060 \%$ of the absolute crack length is considered around the crack tip. A triangular wedge-shaped element (figure 5a) is formed by collapsing the top plane of a brick element along the surface diagonal. The elements with multiple nodes are arranged along different radial lines around the crack tip. These elements are quadratic in behaviour. The mid nodes of the elements in the first radial line are placed at the quarter positions (as shown in figure 5b) to produce the appropriate $1 / r$ singularity as the limit of the plasticity is approached. This element is referred as singular element, which was derived by Blackburn (1976). These elements are capable of sustaining the anticipated large strain as mentioned in the report of Degiorgi \& Matic (1990).

\subsection{Loading and support conditions}

In experiment, pins are inserted through the hole and are held through grip by the jaws of Instron machine. In finite element model, elements at the pinhole possess linear elastic material properties to prevent local effects of nodal loading. The coincident nodes in the wedge shaped elements at the crack tip were left unconstrained to allow appropriate development of crack tip blunting.

\subsection{Linear analysis}

The value of stress intensity factor needed to calculate elastic CTOD was found using the expression,

$$
K_{I}=\sigma_{i j}\left[(2 \pi r)^{1 / 2} /\left(g_{i j}^{I}(\theta)\right)\right],
$$

where, $g_{i j}^{I}(\theta)$ is function of $\theta$ and $\sigma_{i j}$ is the stress value of the node having maximum displacement at radius $r$, and an angle $\theta$ with the crack plane (figure 5b). Now using (4) the elastic CTOD is determined. 


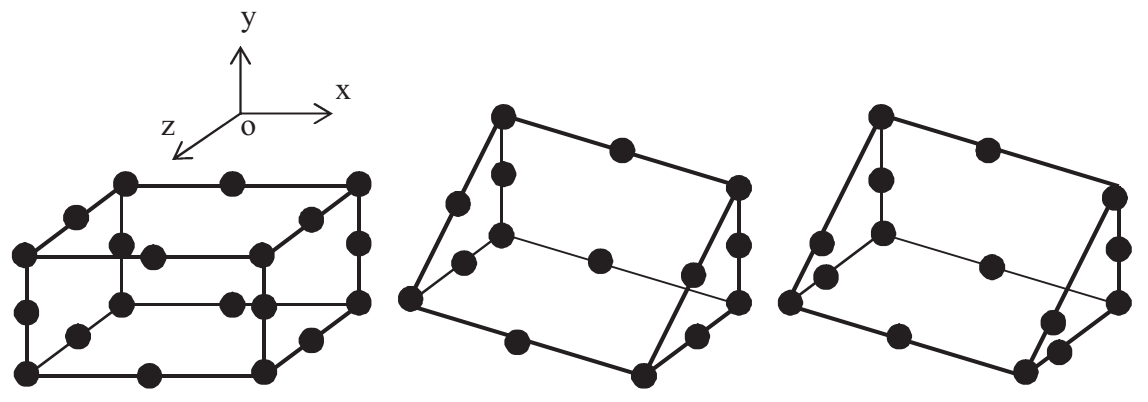

(a)

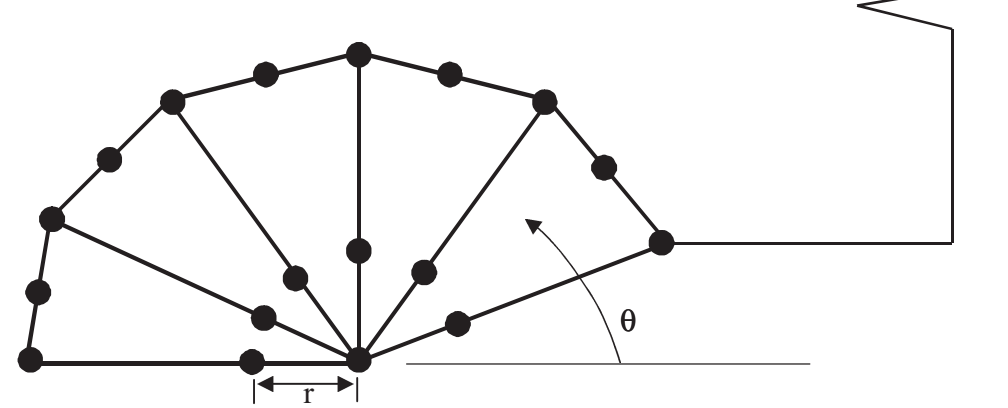

(b)

Figure 5. (a) Creation of crack tip elements (3-D, 20-noded structural solid). (b) Determination of stress value at the node having maximum displacement.

\subsection{Nonlinear analysis}

Elastic-plastic finite element analysis can be considered as an extension of elastic by incorporating extra conditions pertaining to nonlinear plasticity conditions due to Gdouts \& Papkalitakis (1987). Nonlinear material behaviour is modelled by using the incremental theory of plasticity. The Von Mises yield criterion is considered to be valid for these materials.

The elastic-plastic process requires continuous assessment of stress and plastic strain at all points of the structure, as the applied load increases. Hence the load is applied in a sequence of relatively small increments, and within each step a check on stress and equilibrium is made. As loading starts, the program starts to iterate the stress above the yield stress to consider the plastic effects. The whole nonlinear curve is considered to consist of a number of straight lines, each being designated as a load step. With the help of this analysis, the value of plastic CTOD $\left(\delta_{p l}\right)$ and crack tip necking $\left(\delta_{n}\right)$ is determined at the same node considered in linear analysis. The results of plastic CTOD and crack tip necking are shown in figures $6 \mathrm{a}$ and $\mathrm{b}$ respectively for S1 specimen. The values of elastic CTOD and plastic CTOD are used to find equivalent fracture toughness similar to experimental method. The computed values of $\delta_{e l}, \delta_{p l}, \delta_{c}, \delta_{n}$ and $K_{Q}$ are listed in table 3 . 
(a)

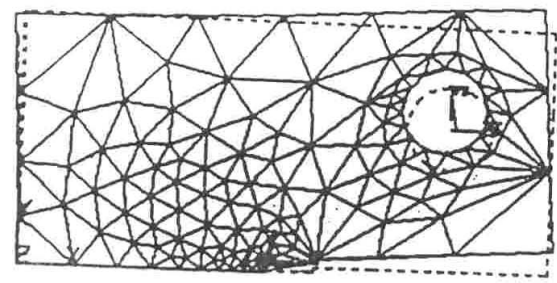

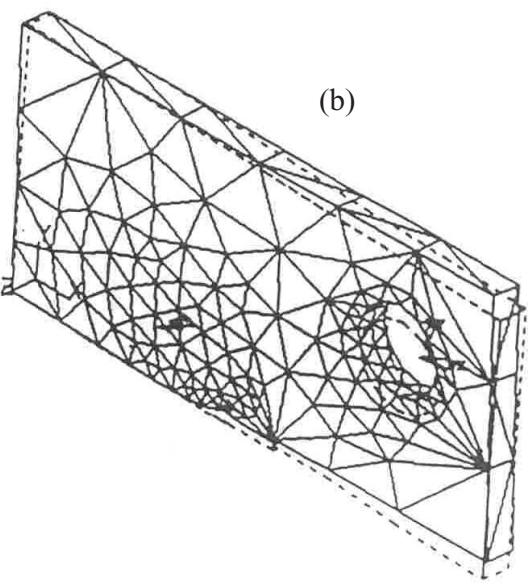

Figure 6. (a) Crack tip opening displacement. (b) Crack tip necking.

The variation of equivalent fracture toughness $\left(K_{Q}\right)$ with the thickness of the steel sheets is shown in figure 7. In the same figure, three reported values (Liu 1981) of $K_{c}$ for HY80 steel (corresponding closely to thickness range considered here) are also incorporated. Figure 7 indicates that the trend of the present results is similar to those obtained by Liu (1981), and in all the four reports the magnitude of fracture toughness of thin sheets increases with increase in thickness, unlike that for thick plates as reported by Srawley \& Brown (1975). The value of $K_{Q}$ reaches a maximum value corresponding to a critical point thickness, after which, it starts decreasing as and when a plane strain condition is reached. In the general yielding zone a dominant shear lip formation is observed on the fracture surface unlike that of a mixed mode formation (after a critical point thickness) in thick plates.

\section{Conclusions}

Empirical engineering simulative tests of thin sheets lack fundamental scientific basis to characterise fracture behaviour in thin sheets. There is a need to understand fundamentals of

Table 3. Finite element results on different fracture parameters.

\begin{tabular}{ccccccc}
\hline $\begin{array}{c}\text { Specimen } \\
\text { code } \\
\text { no. }\end{array}$ & $\begin{array}{c}\text { Thickness } \\
B\end{array}$ & \multicolumn{5}{c}{ FEM CTOD results } \\
\cline { 3 - 7 } & $(\mathrm{mm})$ & $\begin{array}{c}\delta_{e l} \\
(\mathrm{~mm})\end{array}$ & $\begin{array}{c}\delta_{p l} \\
(\mathrm{~mm})\end{array}$ & $\begin{array}{c}\delta_{c} \\
(\mathrm{~mm})\end{array}$ & $\begin{array}{c}K_{Q} \\
\left(\mathrm{MPa} \mathrm{m}^{1 / 2}\right)\end{array}$ & $\begin{array}{c}\delta_{n} \\
(\mathrm{~mm})\end{array}$ \\
\hline S1 & 1.18 & 0.0410 & 0.526 & 0.567 & 199.72 & 0.478 \\
S2 & 1.38 & 0.0428 & 0.581 & 0.624 & 209.52 & 0.532 \\
S3 & 1.64 & 0.0450 & 0.639 & 0.684 & 219.36 & 0.582 \\
S4 & 1.69 & 0.0473 & 0.769 & 0.816 & 239.59 & 0.699 \\
\hline
\end{tabular}




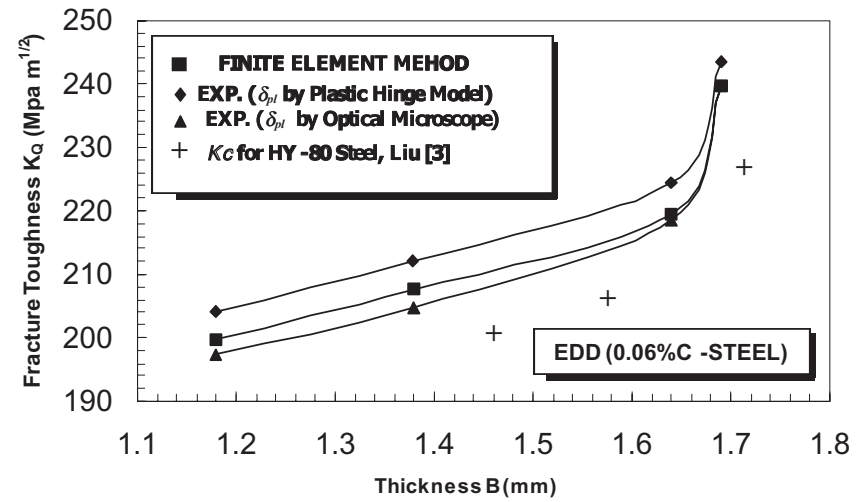

Figure 7. Variation of equivalent fracture toughness $\left(K_{Q}\right)$ with thickness of specimen.

fracture behaviour as these tests give relative engineering index of formability. In fracture mechanics, the engineering criterion is to measure the load levels at which crack initiates and propagates. In the present work, a similar principle is extended to predict fracture limits using fracture-based design parameters like critical load and critical CTOD.

In this investigation, two distinct deviations from the suggested guidelines of Liu and his co-workers are considered for computing the fracture criteria of thin sheets. First, since crack initiation event can be physically determined with the load drop phenomenon, fracture criterion is considered to correspond to the value of critical load $P_{c}$ and critical CTOD $\left(\delta_{c}\right)$. Second, since for thin sheets the magnitude of CTOD is high enough, an obvious simplification leads to the elimination of the plastic part of CTOD $\left(\delta_{p l}\right)$ measurements by Moire fringe technique or estimation of crack tip necking $\left(\delta_{n}\right)$ by replica technique because CTOD can be simply estimated with the help of either plastic hinge model or optical microscope.

The variation of critical CTOD $\left(\delta_{c}\right)$ and equivalent fracture toughness $\left(K_{Q}\right)$ with the thickness of sheets indicates that the trend of FE results is in good agreement (within 1-4\%) with experimental results and in both the reports, the magnitude of fracture toughness increases with increase in thickness unlike that for thick plates as reported by Srawley \& Brown (1975). The estimated values of plastic CTOD by all the three methods: OM, PHM and FE are in good agreement. In addition to this, the amount of crack tip necking $\left(\delta_{n}\right)$ could be precisely determined with the help of FE analysis, which otherwise a difficult task to measure. In FE results, the amount of crack tip necking is within 9\% of plastic CTOD and agrees Liu's report.

In summary, a new approach is suggested here for determining fracture criterion of thin sheets using load drop technique, which assists in detecting the physical event of crack initiation. More results on similar investigations are expected to establish the generalization of this specific observation.

The authors are grateful to the University Grant Commission (UGC), New Delhi for financial support. The authors are also grateful to the Scientific Services Division, Tata Iron and Steel Co. Ltd., Jamshedpur, for providing the EDD steel sheet material. 


\section{List of symbols}

$\begin{array}{ll}a & \text { Crack length; } \\ B & \text { thickness of specimen; } \\ \Delta B & \text { change in thickness at the crack tip; } \\ \text { CTOD } & \text { crack tip opening displacement; } \\ \text { CTOD }{ }_{c} & \text { critical crack tip opening displacement; } \\ E & \text { elastic modulus; } \\ K & \text { stress intensity factor; } \\ K_{c} & \text { fracture toughness of thin sheets; } \\ K_{Q} & \text { equivalent fracture toughness; } \\ P_{c} & \text { critical load; } \\ r & \text { distance of node from crack tip; } \\ r_{p l} & \text { plastic rotational factor; } \\ S_{Y} & \text { yield strength; } \\ V_{l l}, V_{e l}, V_{p l} & \text { load line, elastic load line and plastic load line displacement resplectively; } \\ W & \text { width of specimen; } \\ \varepsilon_{z} & \text { crack tip strain in thickness direction; } \\ \delta_{e l}, \delta_{p l}, \delta_{c} & \text { elastic, plastic and critical CTOD respectively; } \\ \delta_{n} & \text { crack tip necking; } \\ v & \text { Poisson's ratio; } \\ \sigma_{i j} & \text { nodal stress value; } \\ \theta & \text { nodal angle with reference to crack plane. }\end{array}$

\section{References}

ASTM 1991 American Society for Testing and Materials (ASTM). E399-91, Philadelphia, PA

ASTM 1989 ASTM standard test method for crack-tip opening displacement (CTOD) fracture toughness measurement. E1290-89, Philadelphia, PA

Blackburn W S 1976 On the use of singular finite elements in linear fracture mechanics. Int. J. Numer. Methods Eng. 10: 25-37

Degiorgi V G, Matic P 1990 An experimental and computational investigation of crack growth in three-point bend fracture specimens. Eng. Fracture Mech. 37: 1039-1058

Dugdale D S 1960 Yielding of steel plates containing slits. J. Mech. Phys. Solids 8: 100-108

Gdouts E E, Papkalitakis G 1987 Crack growth initiation in elastic-plastic materials. Int. J. Fracture 32: $143-156$

Kumar A N 1991 A new approach for CTOD evaluation in slow crack growth situations. Eng. Fracture Mech. 40: 1089-1103

Kumar A N 1995 Modeling of rotational factor in notched bend specimen under general and local yield situation. Theor. Appl. Fracture Mech. 24: 33-46

Liu H W 1981 Fracture mechanics of ductile and tough materials and its applications to energy related structures (The Hague: Martinus Nijhoff) pp 189-198

Liu H W, Ke J S 1976 Thickness effect on crack tip deformation of fracture. Eng. Fracture Mech. 8: 425-436

Liu H W, Kuo A S 1978 Fracture toughness of thin and tough plates. Int. J. Fracture 14: R109-R112

Merkle, Corten 1974 J. Press. Vessel Technol. 96: 286-292

Rao K P, Mohan E V R 2000 Direct evaluation of sheet metal forming properties under various deformation conditions. Fracture and strength of solids (Brandrain, Switzerland: Trans. Tech. Publications) pp 509-516 
Srawley J E, Brown W F 1975 Fracture toughness testing and its applications. ASTM STP No. 381, Philadelphia, PA, pp 133-198

Panontin T N, Makino A, Williams J F 2000 Crack tip opening displacement estimation formulae for C(T) specimens. Eng. Fracture Mech. 67: 293-301

Wu P D, Graf A, Jain M, MacEwen S R 2000 On alternative representation of forming limits. Fracture and strength of solids (Brandrain, Switzerland: Trans. Tech. Publications) pp 304-309 